\title{
Improvement of Core Performance by Introduction of Moderators in a Blanket Region of Fast Reactors
}

\author{
Toshio Wakabayashi \\ Department of Quantum Science and Energy Engineering, Tohoku University, 6-6-01-2 Aramaki Aoba, Aoba-ku, \\ Sendai 980-8579, Japan \\ Correspondence should be addressed to Toshio Wakabayashi; toshio.wakabayashi@qse.tohoku.ac.jp
}

Received 4 September 2012; Accepted 4 February 2013

Academic Editor: Wei Shen

Copyright (C) 2013 Toshio Wakabayashi. This is an open access article distributed under the Creative Commons Attribution License, which permits unrestricted use, distribution, and reproduction in any medium, provided the original work is properly cited.

An application of deuteride moderator for fast reactor cores is proposed for power flattening that can mitigate thermal spikes and alleviate the decrease in breeding ratio, which sometimes occurs when hydrogen moderator is applied as a moderator. Zirconium deuteride is employed in a form of pin arrays at the inner most rows of radial blanket fuel assemblies, which works as a reflector in order to flatten the radial power distribution in the outer core region of MONJU. The power flattening can be utilized to increase core average burn-up by increasing operational time. The core characteristics have been evaluated with a continuous-energy model Monte Carlo code MVP and the JENDL-3.3 cross-section library. The result indicates that the discharged fuel burn-up can be increased by about $7 \%$ relative to that of no moderator in the blanket region due to the power flattening when the number of deuteride moderator pins is 61 . The core characteristics and core safety such as void reactivity, Doppler coefficient, and reactivity insertion that occurred at dissolution of deuteron were evaluated. It was clear that the serious drawback did not appear from the viewpoints of the core characteristics and core safety.

\section{Introduction}

In order to flatten radial power distribution in fast reactors, ordinary fast reactor cores employ two enrichment zones where outer zone has higher plutonium enrichment. Even in such design the power is dropped at the outer zone of the outer core due to the neutron leakage at the peripheral regions. Zirconium hydride has advantages of high moderation ratio as well as the stability to neutron irradiation as no gas emission occurs at neutron absorption. On the other side, it sometimes induces thermal spikes at the fuel pins adjacent to the moderator zones and reduces breeding ratios due to the large absorption cross section of hydrogen contained even in the fast reactor hard spectrum. However, such features of generating thermal spikes will be useful to increase the power at low power region such as core peripherals if the moderator is appropriately arranged, and it can provide the flattening in power distributions in fast reactors.

There are many studies [1-8] for the application of moderator in fast reactors. When the moderator material is mixed with absorber or long-life fission products (LLFPs) in the fast reactor core, it will offer many advantages in core performances such as an increase in control rod worth or transmutation rate of LLFP [1-5]. The most promising moderator applicable to the fast reactor has been considered to be zirconium hydride for a long time. It has many experiences in fast reactor plant applications and designs including the shield of KNK-2 [9] in Germany and that of large fast reactor designs in Japan. An application of a hydride absorber as a control rod material in a fast reactor has been studied $[7,8]$.

The author proposes zirconium deuteride instead of zirconium hydride for flattening power distributions because it has a relatively high moderation ratio and very small neutron absorption cross sections. In this paper, an application of deuteride moderator for fast reactor cores is proposed for power flattening that can mitigate thermal spikes and alleviate the decrease in breeding ratio, which sometimes occurs when hydrogen moderator is applied as a moderator. The power flattening can be utilized to increase core average burn-up by increasing operational time or reducing fuel inventory which can be achieved by the reduction of core height, for example, 
under the same restriction of the maximum linear heat rate. In this study, the power flattening and the increase in the core average burn-up were evaluated under the above assumptions for MONJU core. The influences of core characteristics, such as sodium void reactivity, Doppler coefficient, and control rod worth by the introduction of deuteride moderator were evaluated. In the safety aspect, reactivity insertion occurred at dissolution of deuteron was also evaluated.

\section{Moderator Design and Monju Core}

2.1. Moderator Assembly Design. The evaluated moderators include three types of zirconium compound. One is zirconium deuteride, another is ordinary zirconium hydride and the other is zirconium hydride of $25 \%$ smear density, where the effective volume ratio of the zirconium hydride is diluted to $25 \%$ of the inside cross sectional area of the pin. Such low smear density pins are usually fabricated by employing hollow pellets or pore rich materials.

The reason to select this arrangement is the mitigation of thermal spike, which sometimes occurs even in the fast reactor core including hydride materials. If the moderator is located at core peripherals, thermal spike is not important because linear heat rates of fuel pins are relatively low. This thermal spike can be utilized to enhance the flattening of power distribution if it occurs at low-power regions such as core peripherals.

The moderator pin arrangements in the moderator assembly are selected as parameters. The pin arrangements are shown in Figure 1. For example, the 9-pin moderator assembly contains 9 moderator pins facing the outer core assemblies and 52 depleted uranium oxide pins facing the second row of radial blanket assemblies. In no moderator core case, the moderator pins are replaced to depleted uranium oxide pins.

2.2. MONJU Core. The specifications of the MONJU core [10-12] are listed in Table 1. The core thermal power is $714 \mathrm{MWt}$ and the fuel material is MOX. The core size is $93 \mathrm{~cm}$ in core height and about $180 \mathrm{~cm}$ in core diameter. The radial blanket zone is composed of 3 rows of blanket assemblies. The moderator assemblies are located at the inner most row of the radial blanket zone.

\section{Analysis Method}

The nuclear analysis method is listed in Table 2. A threedimensional continuous energy Monte Carlo Code MVP $[13,14]$ is used with the Japanese cross-section library JENDL3.3 [15] processed adjusted to MVP code.

Typical neutron history number employed is 1000000 divided to 100 batches and other 20 batches are used for generating the initial source distribution. The statistical error of pin power is about $2 \%$ in $1 \sigma$ level.

MVP-BURN (burn-up routine for MVP) [16] has been used to evaluate burn-up characteristics including breeding ratios. The burn-up chain employed is basically an FBR chain preinstalled in MVP-BURN (burn-up routine for MVP).
TABLE 1: Specification of MONJU core.

\begin{tabular}{|c|c|c|}
\hline Items & Unit & Spec. \\
\hline Reactor thermal power & MWt & 714 \\
\hline Core configuration & - & $\begin{array}{l}\text { Homogeneous } 2 \\
\text { region core reactor }\end{array}$ \\
\hline Operation cycle length & days & 123 \\
\hline Core height & $\mathrm{mm}$ & 930 \\
\hline $\begin{array}{l}\text { Number of fuel assemblies } \\
\text { (IC/OC/total) }\end{array}$ & - & $108 / 90 / 198$ \\
\hline $\begin{array}{l}\text { Number of moderator } \\
\text { assemblies }\end{array}$ & - & 54 \\
\hline $\begin{array}{l}\text { Total number of pins in the } \\
\text { moderator assembly }\end{array}$ & & 61 \\
\hline Number of Moderator pins & & 9 or 24 or 61 \\
\hline $\begin{array}{l}\text { Number of radial blanket } \\
\text { pins }\end{array}$ & & 52 or 37 or 0 \\
\hline Pin diameter & $\mathrm{mm}$ & 10.6 \\
\hline Diameter of moderator & $\mathrm{mm}$ & 9.5 \\
\hline Moderator material & & $\begin{array}{l}\text { Zr deuteride } \\
\text { Zr hydride }\end{array}$ \\
\hline
\end{tabular}

Figure 2 illustrates core maps and moderator assemblies in MONJU core. The inner core zone consists of 6 rows of assemblies and the outer core zone consists of 2 rows of assemblies where each assembly has 169 fuel pins. The pin power is integrated in axial direction over the core height. The radial blanket zone has 3 rows of assemblies containing 61 pins, where the first row consists of moderator assemblies. The moderator assemblies are replaced to normal radial blanket assembly for the no moderator core. The moderator assembly consists of moderator pins facing outer core fuels, which contains zirconium hydride or deuteride in a stainless steel cladding and depleted uranium oxide pins.

For pin-wise power distribution in the second row of the outer core has been evaluated for each pin row as shown in Figure 3. The powers of all pins belonging to each row have been summarized and divided by the number of the pins.

\section{Results and Discussions}

Figure 4 presents the result of pin-wise power peaking factor in the 2-row assembly of the outer core. The radial power peaking of no moderator case shows a monotone decrease while that of other cases produces thermal spike at the pins near to the moderator.

The zirconium hydride $\left(\mathrm{ZrH}_{1.7}\right)$ case shows the largest spike at the outer pins which peak power is about 3 times of that of the inner most row pins. On the other hand, the peak of the $\mathrm{ZrD}_{1.7}$ case does not exceed the power of the inner pins, and the power distribution over the assembly is flattened relative to that of no moderator case. The $25 \%$ smeared zirconium hydride $\left(25 \% \mathrm{ZrH}_{1.7}\right)$ case has small peak at the outer pins but it has a dip behind the peak.

Figure 5 shows the assembly power peaking factor in radial direction of the core. The power at the second row of the outer core (row no. 8) in the $\mathrm{ZrD}_{1.7}$ case is about the same 
TABLE 2: Analytical method.

\begin{tabular}{|c|c|c|}
\hline Items & Methods & Notes \\
\hline Computation method & $\begin{array}{l}\text { Three-dimensional continuation energy } \\
\text { Monte Carlo analysis code } \\
\text { MVP (Burn-up routine is MVP-BURN) }\end{array}$ & $\begin{array}{l}1,200,000 \text { neutron histories with } 120 \\
\text { Batches, } \\
\text { Initial } 20 \text { batches are run to establish the } \\
\text { initial neutron source distribution. }\end{array}$ \\
\hline Nuclear data & JENDL-3.3 library & \\
\hline Calculation model & Pin heterogeneous model & \\
\hline
\end{tabular}

TABLE 3: (a) Dependence of core performances on the number of $\mathrm{ZrD}_{1.7}$ moderator pins. (b) Dependence of core performances on the number of $\mathrm{ZrH}_{1.7}$ moderator pins.

(a)

\begin{tabular}{lcccc}
\hline $\begin{array}{l}\text { Number of moderator } \\
\text { Pins }\end{array}$ & $\begin{array}{c}\text { Power peaking factor } \\
\text { in core }\end{array}$ & $\begin{array}{c}\text { Power peaking factor } \\
\text { of 2nd row assembly } \\
\text { in outer core }\end{array}$ & $\begin{array}{c}\text { Power peaking factor } \\
\text { in blanket assembly }\end{array}$ & $\begin{array}{c}\text { Increase of core } \\
\text { average burn-up (\%) }\end{array}$ \\
\hline 0 & 1.233 & 1.173 & 1.420 & - \\
9 & 1.253 & 1.130 & 1.703 & 0.9 \\
18 & 1.231 & 1.095 & 1.251 & 2.9 \\
24 & 1.230 & 1.141 & 1.927 & 1.2 \\
61 & 1.202 & 1.312 & - & 7.0 \\
\hline
\end{tabular}

(b)

\begin{tabular}{lcccc}
\hline $\begin{array}{l}\text { Number of moderator } \\
\text { pins }\end{array}$ & $\begin{array}{c}\text { Power peaking factor } \\
\text { in core }\end{array}$ & $\begin{array}{c}\text { Power peaking factor } \\
\text { of 2nd row assembly } \\
\text { in outer core }\end{array}$ & $\begin{array}{c}\text { Power peaking factor } \\
\text { in blanket assembly }\end{array}$ & $\begin{array}{c}\text { Increase of core } \\
\text { average burn-up (\%) }\end{array}$ \\
\hline 0 & 1.233 & 1.173 & 1.420 & - \\
9 & 1.236 & 1.373 & 2.223 & 4.7 \\
18 & 1.204 & 1.890 & 1.649 & 7.4 \\
24 & 1.223 & 1.379 & 2.035 & 4.9 \\
61 & 1.264 & 2.748 & - & 8.2 \\
\hline
\end{tabular}

TABLE 4: Comparison of breeding ratio between cores with and without moderator

\begin{tabular}{lcc}
\hline Core & Cycle & $\begin{array}{c}\text { Breeding } \\
\text { ratio }\end{array}$ \\
\hline $\begin{array}{l}\text { Core with 61 deuteride } \\
\text { moderator pins }\end{array}$ & $\begin{array}{l}\text { Equilibrium cycle } \\
\text { Core without moderator pins }\end{array}$ & \begin{tabular}{l} 
Equilibrium cycle \\
\hline
\end{tabular} \\
\hline
\end{tabular}

as that of the inner core (row no. 6), It is considered that the power distribution in the assembly of the 2 nd row of the outer core for the $\mathrm{ZrD}_{1.7}$ case is the most flattened.

Tables 3(a) and 3(b) show the dependence of the power peaking factors and the discharged fuel burn-ups on the number of moderator pins of the $\mathrm{ZrD}_{1.7}$ and $\mathrm{ZrH}_{1.7}$ moderator assemblies located at the first row of radial blanket region in MONJU, respectively. In cases of 18 and 61 pins of $\mathrm{ZrH}_{1.7}$ moderator, it was recognized that these linear heat powers exceed the limit of the maximum liner power because of the large power peaking factors at 2 nd row assembly in the outer core. These results indicate the power peaking factor in the core is the smallest when the number of deuteride moderator pins are 61 , and the core average burn-up can be increased by about $7 \%$ relative to that of no moderator core due to the power flattening.

Comparison of breeding ratio between cores with and without deuteride moderator pins in Table 4, The breeding ratio of the $\mathrm{ZrD}_{1.7}$ case is about $10 \%$ smaller than that of no moderator case. The breeding ratio is closely related to the burn-up reactivity loss, thus the result indicates $\mathrm{ZrD}_{1.7}$ is the most favorable moderator for fast breeder cores among the candidate moderators.

The influences of core characteristics, such as sodium void reactivity, Doppler coefficient, and control rod worth by the introduction of deuteride moderator pins were evaluated.

Comparison of Doppler coefficient between the cores with and without $\mathrm{ZrD}_{1.7}$ moderator pins is shown in Table 5. The absolute value of Doppler coefficient in the core with 61 deuteride moderator pins is about $50 \%$ larger than that in the core without moderator pins because of softening of neutron spectra in fuel region by moderator.

Comparison of sodium void reactivity between the cores with and without $\mathrm{ZrD}_{1.7}$ moderator pins is shown in Table 6. 

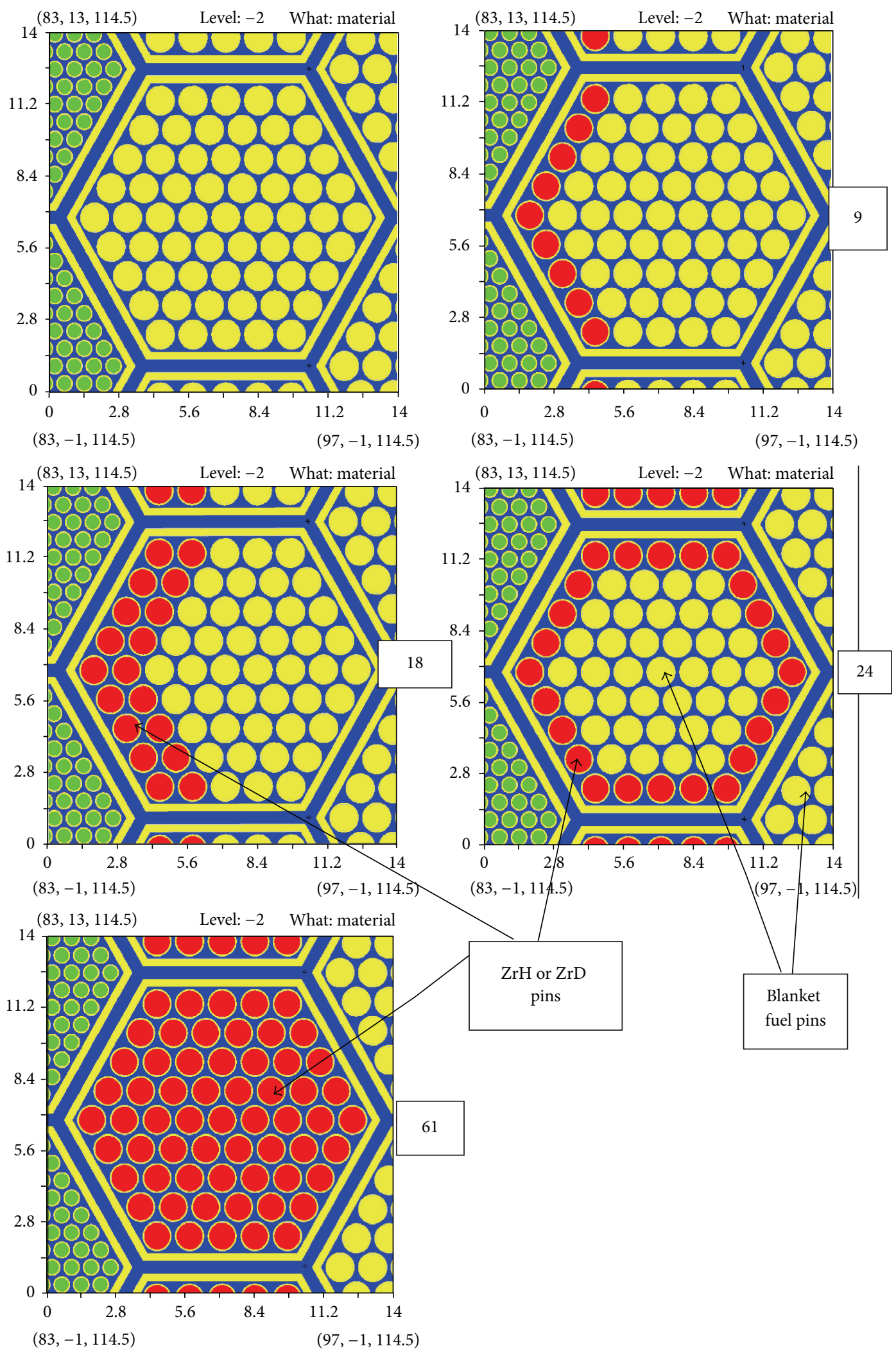

FIgURE 1: Pin arrangements in moderator assembly. 


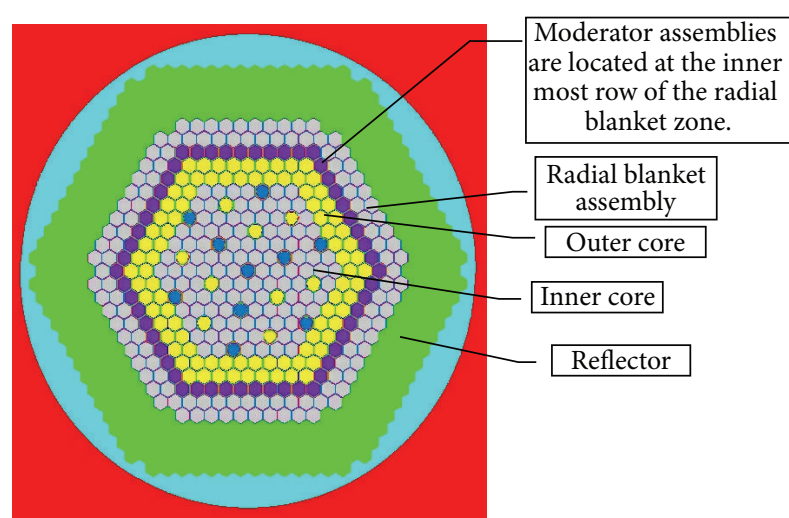

FIGURE 2: Core arrangement of MONJU.

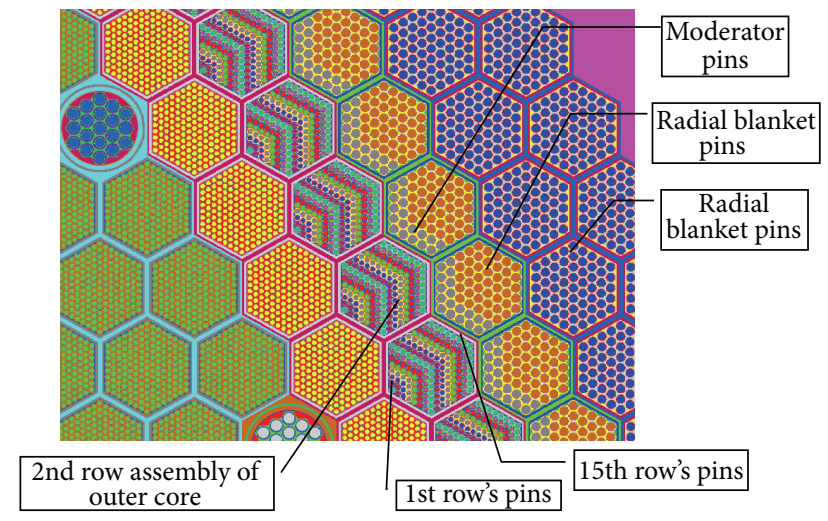

FIGURE 3: Details of pin arrangement at outer core region.

Sodium void reactivity at equilibrium cycle in the core with 61 deuteride moderator pins is a little smaller than that in the core without $\mathrm{ZrD}_{1.7}$ moderator pins. It is considered that the reason of reducing positive sodium void reactivity is softening of neutron spectra in fuel region by moderator. This feature is important from the viewpoint of FBR safety.

Comparison of control rod worth between the cores with and without $\mathrm{ZrD}_{17}$ moderator pins is shown in Table 7. The main control rod worth and backup control rod worth in the core with 61 deuteride moderator pins are, respectively, 5 and $9 \%$ smaller than those in the core without $\mathrm{ZrD}_{1.7}$ moderator pins. It is considered that the neutron flux in the outer core is larger than that of inner core by the introduction of moderator. But, the control rod worth is satisfied with the design requirement.

Figure 6 presents the neutron spectra of outer row pins of the outer most assembly (the outer core second row assembly) for each moderator cases. The spectra of the outer pins show large differences at low-energy regions among different moderator cases.

The linear power of the moderator was two orders below that of the fuel pins around them because the main energy source is gamma deposition generated at the core fuel. The neutrons by gamma-n reactions in $\mathrm{ZrD}_{1.7}$ are roughly estimated five orders below those of neutron generations of MONJU at the normal operation.

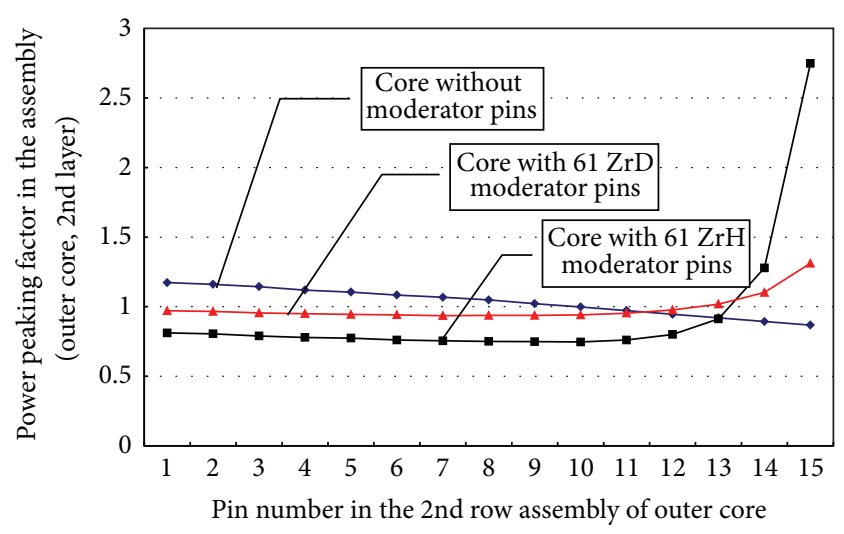

FIGURE 4: Pin wise power peaking factor in the 2 row assembly of the outer core.

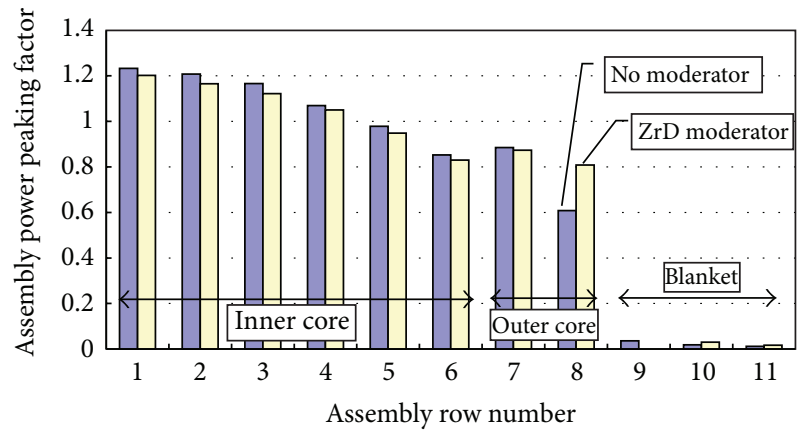

FIgURE 5: Assembly averaged pin power distribution in radial direction.

TABLE 5: Comparison of Doppler coefficient between cores with and without moderator.

\begin{tabular}{lcc}
\hline Core & Cycle & $\begin{array}{c}\text { Doppler coefficient } \\
\left(\Delta k / k k^{\prime} / \mathrm{dT} / T\right)\end{array}$ \\
\hline $\begin{array}{l}\text { Core with 61 deuteride } \\
\text { moderator pins }\end{array}$ & Equilibrium cycle & $-9.86 E-3$ \\
$\begin{array}{l}\text { Core without moderator } \\
\text { pins }\end{array}$ & Equilibrium cycle & $-6.70 E-3$ \\
\hline
\end{tabular}

TABLE 6: Comparison of sodium void reactivity between cores with and without moderator.

\begin{tabular}{lcc}
\hline Core & Cycle & $\begin{array}{c}\text { Sodium void } \\
\text { reactivity } \\
\left(\% \Delta k / k k^{\prime}\right)\end{array}$ \\
\hline $\begin{array}{l}\text { Core with 61 deuteride } \\
\text { moderator pins } \\
\begin{array}{l}\text { Core without moderator } \\
\text { pins }\end{array}\end{array}$ & 1.05 \\
\hline
\end{tabular}

One problem of the hydride use in fast reactor is positive reactivity insertion that occurred at the dissolution of hydrogen. The dissolution of the deuterium will also occur in zirconium deuteride, though the penetration rate of the deuterium across the cladding is considered to be smaller than that of hydrogen due to the larger atomic 


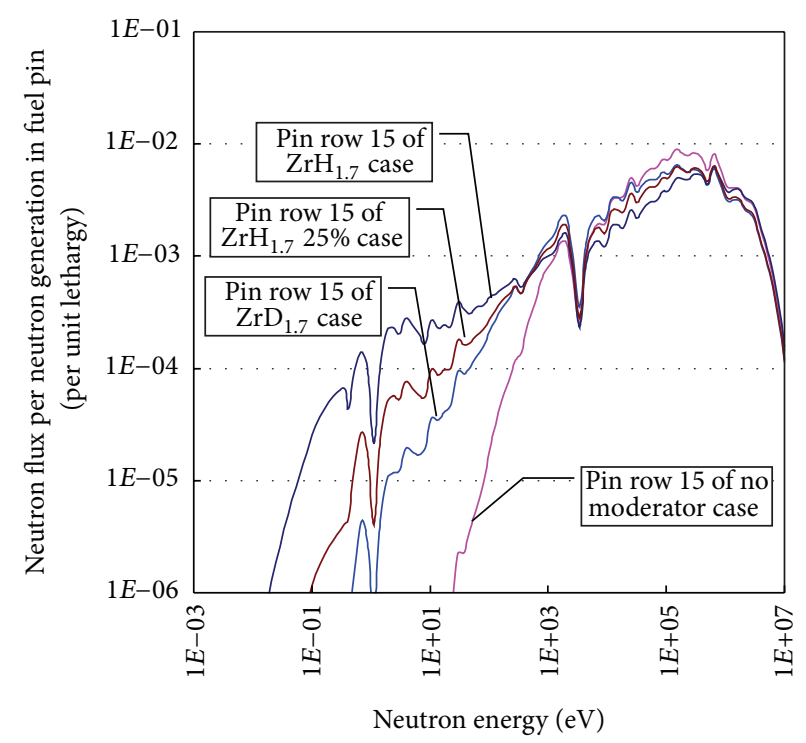

FIGURE 6: Neutron spectra of outer row pins of outer core 2nd row fuel assembly.

TABLE 7: Comparison of control rod worth between cores with and without moderator.

\begin{tabular}{llc}
\hline Type of control rods & Core & $\begin{array}{c}\text { Control rod worth } \\
\left(\% \Delta k / k k^{\prime}\right)\end{array}$ \\
\hline & $\begin{array}{l}\text { Core with 61 } \\
\text { deuteride moderator } \\
\text { pins }\end{array}$ & 8.13 \\
$\begin{array}{l}\text { Main control rods } \\
\text { (13 rods) }\end{array}$ & $\begin{array}{l}\text { Core without } \\
\text { moderator pins } \\
\text { Core with 61 } \\
\text { deuteride moderator } \\
\text { pins } \\
\text { Core without } \\
\text { moderator pins }\end{array}$ & 6.51 \\
$\begin{array}{l}\text { Back-up control rods } \\
\text { (6 rods) }\end{array}$ & 6.08 \\
\hline
\end{tabular}

TABLE 8: Reactivity insertion occurred at dissolution of deuteron.

\begin{tabular}{lc}
\hline Ratio of deuteron in moderator pin & Reactivity $(\% \Delta \rho)$ \\
\hline 1.0 & - \\
0.9 & 0.029 \\
0.7 & 0.103 \\
0 & 0.255 \\
\hline
\end{tabular}

mass. The reactivity insertion by the dissolution of deuterium was evaluated. The reactivity insertion by the dissolution of deuterium is about $+0.255 \% \% \Delta \rho$ as shown in Table 8 . It is considered that the reason of positive reactivity is hardening of neutron spectra in moderator region by the dissolution of deuterium. The values of reactivity insertion are below $1 \$$.

Deuterium will be transmuted to Tritium by neutron absorption where the generation rate of Tritium is estimated to be about 2 decades smaller than that generated from B-10 $(n$, alpha) T reaction in the boron carbide of the control rods.

\section{Conclusions}

An application of deuteride moderator for fast reactor cores is proposed for power flattening that can mitigate thermal spikes and alleviate the decrease in breeding ratio, which sometimes occurs when hydrogen moderator is applied as a moderator. Zirconium deuteride is employed in a form of pin arrays at the inner most rows of radial blanket fuel assemblies, which works as a reflector in order to flatten the radial power distribution in the outer core region of MONJU. The power flattening can be utilized to increase core average burn-up by increasing operational time. The core neutronics has been evaluated with a continuous-energy model Monte Carlo code MVP and the JENDL-3.3 cross-section library. The result indicates that the power peaking factor in the core is the smallest when the number of deuteride moderator pins is 61 , and the core average burn-up can be increased by about $7 \%$ relative to that of no moderator core due to the power flattening. Major core characteristics and core safety including sodium void reactivity, Doppler coefficient, control rod worth and reactivity insertion that occurred at dissolution of deuteron were also evaluated. The breeding ratio of the deuteride case is a little less than that of no moderator case. It is also clear that the influence of major core characteristics and safety aspect by the introduction of deuteride moderator is small.

The present study indicates that the use of deuteride moderators in the blanket region has a large potential to improve performances of FBR cores.

\section{Acknowledgments}

The author deeply appreciates Dr. T. Yokoyama of Toshiba Nuclear Engineering Services Corporation, Mr. Akira Nagata and Mr. Y. Tsuboi of Toshiba Corporation, and Mr. S. Aoyagi of ISA Corporation for their cooperation and advices. Present study includes the results of "Study on Optimization of Core Arrangement of Core Fuel and Blanket Fuel on FBR" entrusted to "Tohoku University" by the Ministry of Education, Culture, Science and Technology of Japan (MEXT).

\section{References}

[1] T. Wakabayashi, "Transmutation characteristics of MA and LLFP in a fast reactor," Progress in Nuclear Energy, vol. 40, no. 3-4, pp. 457-463, 2002.

[2] Y. Tachi, T. Wakabayashi, and T. Yokoyama, "Study on target fabrication for LLFP transmutation by fast reactors," in Proceedings of the International Conference on the Nuclear Fuel Cycle, 2009.

[3] T. Yokoyama, T. Wakabayashi, Y. Tachi, N. Takaki, and S. Matsuyama, "New target concepts for increase in transmutation rate of LLFP in FBR recycle system," in Proceedings of International Conference on the Nuclear Fuel Cycle, 2009.

[4] Y. Tachi and T. Wakabayashi, "Candidate Iodides for LLFP transmutation in FR core," Transactions of the American Nuclear Society, vol. 103, pp. 268-269, 2010.

[5] T. Yokoyama, T. Wakabayashi, Y. Tachi, and A. Nagata, "Increase in transmutation rate of long-life FP by employing deuteride moderator in fast reactors," in Proceedings of the International 
Congress on Advances in Nuclear Power Plants, pp. 536-543, 2011.

[6] D. R. Olander and M. Ng, "Hydride fuel behavior in LWRs," Journal of Nuclear Materials, vol. 346, no. 2-3, pp. 98-108, 2005.

[7] T. Yokoyama, K. Konashi, T. Iwasaki, T. Terai, and M. Yamawaki, "Local-spectrum-modified fast reactor cores with hydrides," in Proceedings of the International Congress on Advances in Nuclear Power Plants (ICAPP '06), pp. 2492-2498, June 2006.

[8] T. Iwasaki and K. Konashi, "Development of hydride absorber for fast reactor-application of hafnium hydride to control rod of large fast reactor," Journal of Nuclear Science and Technology, vol. 46, no. 8, pp. 874-882, 2009.

[9] W. Marth, The History of the Construction and Operation of the German KNK II Fast Breeder Power Plant, vol. 5456 of KfK, 1994.

[10] S. Sawada, T. Suzuki, Y. Okimoto, K. Sasaki, T. Deshimaru, and F. Nakashima, "Reactivity characteristics evaluations of the initial core of Monju," in International Conference on the Physics of Reactors (PHYSOR '96), vol. 2, p. E-76, Mito, Japan, September 1996.

[11] K. Sugino and T. Iwai, "MONJU experimental data analysis and its feasibility evaluation to build up the standard data base for large FBR nuclear core design," in Proceedings of the American Nuclear Society Topical Meeting on Physics of Reactors (PHYSOR '06), American Nuclear Society, Vancouver, Canada, September 2006.

[12] K. Ito and T. Yanagisawa, "Last twenty years experiences with fast reactors in Japan," in Proceedings of the International Conference on Fast Reactors and Related Fuel Cycles: Challenges and Opportunities (FR '09), pp. 7-11, Kyoto, Japan, December 2009.

[13] T. Mouri, W. Sato, M. Uematsu, T. Hazama, and T. Suzuki, "Monju core physics test analysis with various nuclear data libraries," in International Conference on Fast Reactors and Related Fuel Cycles: Challenges and Opportunities (FR '09), Kyoto, Japan, December 2009.

[14] Y. Nagaya, K. Okumura, T. Mori, and M. Nakagawa, "MVP/GMVPII: general purpose Monte Carlo codes for neutron and photon transport calculations based on continuous energy and multi-group methods," JAERI-Report 1348, Japan Atomic Energy Research Institute, 2005.

[15] K. Shibata, T. Kawano, T. Nakagawa et al., "Japanese evaluated nuclear data library version 3 revision-3: JENDL-3.3," Journal of Nuclear Science and Technology, vol. 39, no. 11, pp. 1125-1136, 2002.

[16] K. Okumura, T. Mori, M. Nakagawa, and K. Kaneko, "Validation of a continuous-energy Monte Carlo burn-up code MVP-BURN and its application to analysis of post irradiation experiment," Journal of Nuclear Science and Technology, vol. 37, no. 2, pp. $128-138,2000$. 


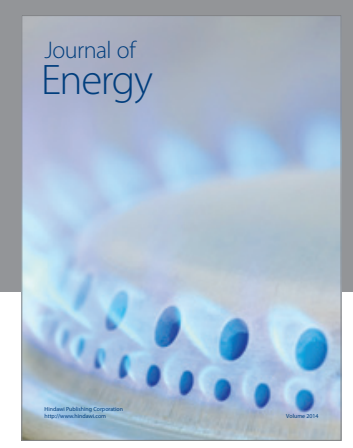

Journal of

Industrial Engineering
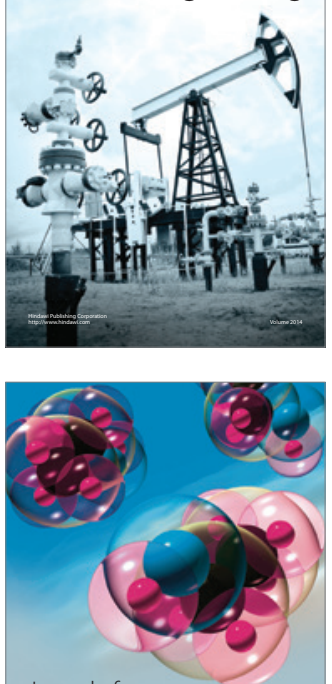

Fuels
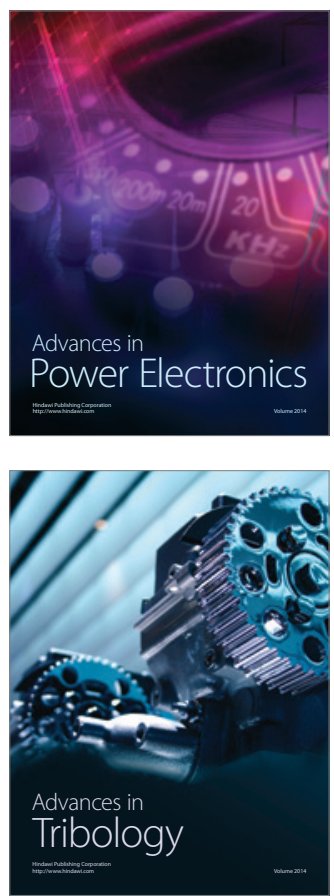

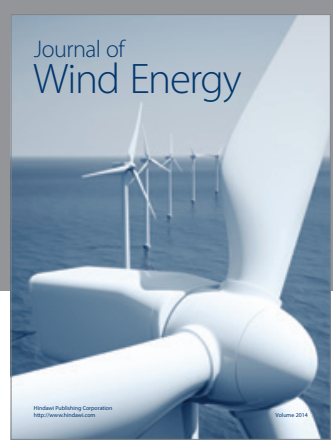

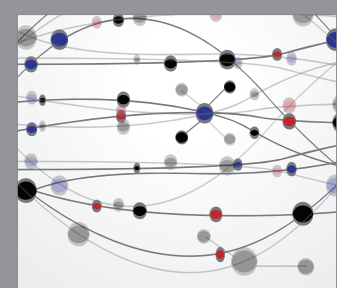

The Scientific World Journal

Submit your manuscripts at http://www.hindawi.com

Journal of

Structures
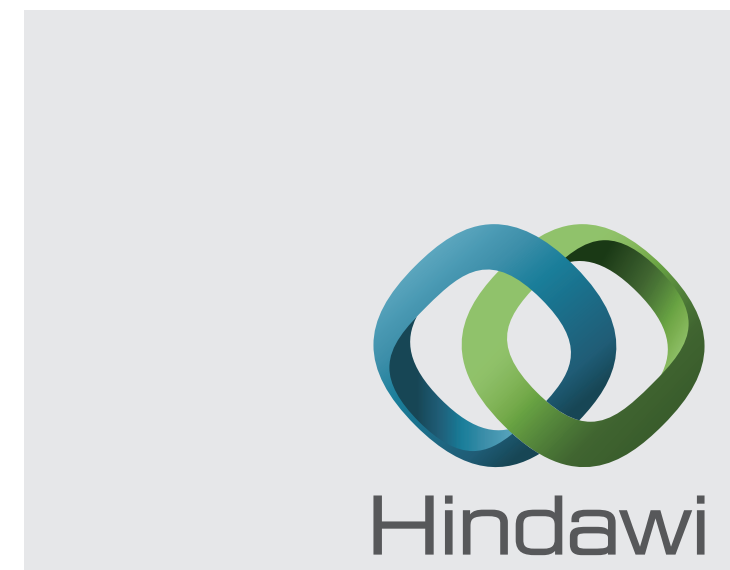

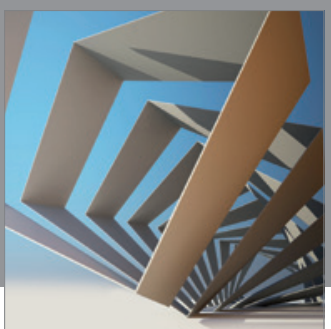

Rotating

Machinery
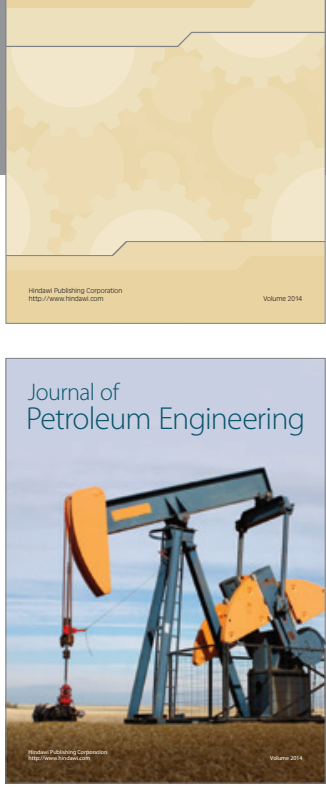

Journal of

Solar Energy
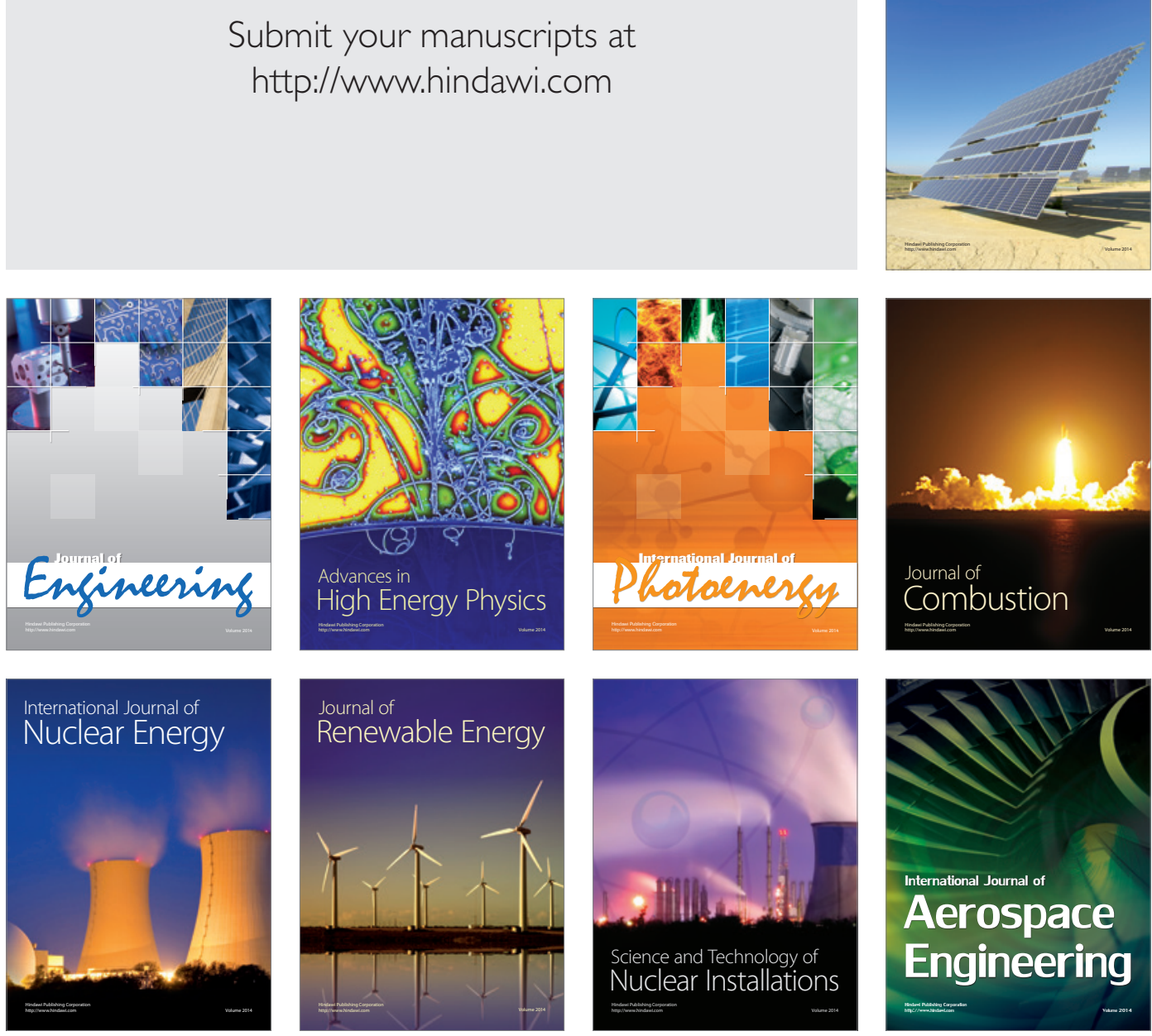